\title{
RESENHAS REVIEWS
}

\author{
Maria Eunice QUILICI GONZALES* \\ João de Fernandes TEIXEIRA* \\ Marcos Barbosa de OLIVEIRA*
}

WOODFIELD, A.R. - Teleology. Cambridge, England, Cambridge Univ. Press, 1976. 232 p.

Andrew Woodfield em Teleology desenvolve um estudo sobre a natureza da teleologia, discutindo a estrutura lógica, as variedades e os usos das explicações teleológicas. A obra divide-se em cinco partes.

A primeira parte (Caps. 1 e 2) apresenta uma introdução ao tema. A partir da definição de teleologia como "a doutrina ou estudo dos fins ou causas finais"** o autor sugere que se substitua o termo "causa final" por "propósito" e passa então a investigar a natureza das questões concernentes à teleologia. Estas questões dizem respeito à relação entre coisas e propósitos. Interessa ao investigador saber se uma determinada entidade tem um propósito ou age com o fim de realizar um propósito. Em caso afirmativo, trata-se de investigar qual é esse propósito.

Duas teses radicalmente opostas sobre a teleologia são inicialmente abordadas por Woodfield. Uma delas afirma que tudo no universo tem um propósito, a outra diz que nada tem propósito. De modo a poder discutí-las o autor aponta para a necessidade de se esclarecer o que significa uma coisa ter ou não um propósito. Sem pretender dar um tratamento histórico exaustivo à ques- tão, esboça uma breve história da teleologia a partir de Aristóteles, percorrendo Bacon, Leibniz, Kant e Darwin na expectativa de que isso o auxiliará a situar o assunto e a mostrar a necessidade de uma abordagem analítica do tema.

O histórico esboçado por Woodfield mostra que a ciência moderna tem sido hostil para com as explicações teleológicas, sendo opinião dominante entre os filósofos e os cientistas, desde a Renascença, que elas são obscuras e animistas, isto é, que elas pressupõem que as coisas a serem explicadas têm uma mente, ou então que elas invocam um ser sobrenatural que direciona o curso dos eventos. Ao analisar as razões alegadas pelos filósofos que justificariam a hostilidade dos mesmos em relação às explicações teleológicas, Woodfield chama a atenção do leitor para a relevância do estudo da teleologia na ciência e na filosofia modernas, bem como para as dificuldades envolvidas nesse tipo de estudo. Ele ressalta no primeiro capítulo que a primeira tarefa a ser realizada pelo estudioso da teleologia consiste em tornar absolutamente claro o que é teleologia; o que significa exatamente ver um fenômeno teleologicamente;

\footnotetext{
* Departamento de Filosofia - Faculdade de Educação, Filosofia, Ciências Sociais e da Documentação - UNESP — 17.500 - Marília - SP.

** Citação de Woodfield, A. (p.1), extraída de Oxford English Dictionary.
} 
WOODFIELD, A.R. - Teleogy. Cambridge, England, Cambridge Univ. Press, 1976. 232 p. RESENHAS. Trans/Form/Ação, São Paulo, 6: 53-60, 1983.

o que é um conceito teleológico e o que é uma linguagem teleológica.

A seguir, no capítulo 2, o autor descreve o seu método de análise para abordar tais questões. Esse método pode ser resumido em três etapas. A primeira consiste em demarcar provisoriamente a área de estudo através de um procedimento lingüístico que permite identificar explicações teleológicas independentemente de considerações acerca do significado das mesmas. Esse procedimento envolve a definição do conceito de descrição teleológica, daqui para a frente $T D$, do inglês "teleological description". As TDs são enunciados feitos através de sentenças teleológicas, ou seja, sentenças do tipo "O homem correu para pegar o trem" ou qualquer outra que contenha expressões tais como "com o propósito de", "de modo a", "com a finalidade de", "para", etc. A segunda etapa do método consiste em admitir que algumas TDs podem ser literalmente verdadeiras. Dada essa premissa básica - que as TDs podem ser objetivamente verdadeiras ou falsas a terceira etapa do método consiste em investigar sob que circunstâncias as TDs são verdadeiras. A idéia central subjacente a essa abordagem analítica consiste em descobrir as condições necessárias e suficientes para a verdade das TDs. O foco polêmico desse debate metodológico consiste na pressuposição de Woodfield de que a presença de conectivos teleológicos nas TDs deve ser justificada por referência à presença de aspectos objetivos naquilo que essas TDs descrevem. Em contraposição a este ponto de vista, Woodfield refere-se àquilo que ele chama de 'projecionismo', ou seja, a concepção de acordo com a qual "as TDs projetam sobre as coisas uma propriedade que elas de fato não possuem" (p.26). O final da primeira parte do livro enuncia os principais desdobramentos das quatro outras partes que o compõem.

$\mathrm{Na}$ segunda parte (Caps. 3-6) Woodfield expõe e critica algumas teorias do comportamento propositado (goal-directed-behaviour), as quais ele denomina teorias comportamentais (behaviourist theories). Tais teorias possuem uma característica em comum, a saber, uma concepção segundo a qual os comportamentos teleológicos exibem uma constância em relação a seus estágios finais. Nesse sentido podem ser descritas como teleológicas as seqüências de comportamentos que convergem para um fim, não importando a variedade de rotas ou caminhos percorridos nem as possíveis variações das condições iniciais que possam assumir essas seqüências. A análise de Woodfield desdobra-se em quatro momentos sucessivos, percorrendo as teorias de R. Braithwaite, G. Sommerhoff e Ch. Taylor, finalizando com uma avaliação dos pressupostos comuns por elas exibidos.

A primeira teoria analisada, a de $\mathrm{R}$. Braithwaite* centra-se essencialmente na noção de plasticidade. A plasticidade pode ser entendida como a realização de uma determinada meta numa variedade de circunstâncias. Em outras palavras, se um determinado percurso para a realização do estágio final de uma seqüência de ações não se torna exeqüível, um sistema dotado de plasticidade deve ser capaz de utilizar seqüências alternativas de estágios que culminem na realização da etapa final ou meta. De acordo com a teoria desenvolvida por R. Braithwaite, os comportamentos propositados caracterizam-se por exibirem plasticidade.

As críticas elaboradas por Woodfield às concepções de R. Braithwaite baseiam-se fundamentalmente na existência de contra-exemplos que falseiam a teoria da plasticidade. Alguns desses contra-exemplos ilustram uma especial dificuldade da teoria de $\mathrm{R}$. Braithwaite, qual seja, aqueles casos onde algum obstáculo impede a realização da meta final. $O$ caso invocado para ilustrar esta circunstância é extraído de um artigo de L. Wright:** trata-se de um peixe tentando inutilmente escapar de uma rede, cujo procedimento mostra que um com-

* Braithwaite, R. Scientific Explanation. New York, Harper \& Brothers, 1960. Cap. X.

** Wright, L. - The case against teleological reductionism. British Journal for the Philosophy of Science, 19, 1968-9. 
portamento pode ser dirigido para um fim, e portanto ser subsumido a categoria de comportamento propositado, sem entretanto chegar a realizar seu estágio final. Uma outra deficiência da teoria braithwaiteana é evidenciada através de alguns exemplos de comportamentos dirigidos a fins nos quais se constata a presença de uma pluralidade de metas que podem culminar no mesmo estágio final. Nestes casos, torna-se difícil identificar qual a meta perseguida, o que ressalta o caráter impreciso dos critérios elaborados por R. Braithwaite para caracterizar o comportamento propositado.

O segundo momento da análise das teorias comportamentais (Cap. 4) é dedicado ao exame da concepção de teleologia desenvolvida por G. Sommerhoff em Analytical Biology (1950). Neste estágio de seu trabalho, Woodfield empreende uma detalhada análise das teorias de G. Sommerhoff visando retraçar o conceito de "correlação diretiva" (directive correlation) a partir da qual seria possível obter uma caracterização da natureza dos comportamentos propositados. A estratégia das críticas elaboradas pelo autor de Teleology permanece a mesma: trata-se de mostrar a insuficiência das concepções de G. Sommerhoff através da discussão de alguns contra-exemplos.

A terceira teoria comportamentalista discutida por Woodfield é a de Ch. Taylor exposta no seu trabalho The Explanation of Behaviour (1964). Woodfield procura mostrar que esta teoria não se afasta das demais propostas comportamentalistas, especialmente na medida em que ela omite uma discussão preliminar do conceito de propósito. De acordo com a apresentação esboçada em Teleology, a teoria tayloriana afirma simplesmente que um comportamento pode ser considerado propositado na medida em que ele apresenta um estado terminal, e que seus estágios intermediários encontram-se igualmente direcionados para a produção deste último. Se supusermos a existência de uma regularidade nesse processo, podemos admitir a existência de algo como "leis teleológicas" (T-laws) as quais expressariam a constância de com- portamentos dirigidos a fins. A partir destas leis seria então possível formular um modelo explicativo que subsumisse comportamentos propositados e que assumisse uma forma dedutiva.

As objeções à teoria tayloriana baseiam-se também na existência de contra-exemplos, ou seja, de fenômenos que são passíveis de ser explicados de acordo com o modelo elaborado por $\mathrm{Ch}$. Taylor embora não possam ser considerados efetivamente propositados. O exemplo mais interessante discutido por Woodfield é o do movimento pendular livre, cuja oscilação tende a restaurar o estado de equilíbrio, configurando uma cadeia de estágios com o mesmo estado terminal. Tal cadeia, contudo, não poderia caracterizar um comportamento propositado. Outros fenômenos também poderiam em princípio ser subsumidos a leis que expressassem uma constância quanto a estágios terminais mas nem por isso poderíamos falar de leis teleológicas. A simples instanciação de comportamentos que se relacionem a um estágio futuro não fornece condições suficientes para caracterizar determinados comportamentos como propositados, embora a partir dessas recorrências possamos derivar um conjunto de leis.

Em resumo, podemos afirmar que as críticas elaboradas por Woodfield às concepções de Ch. Taylor não diferem daquelas esboçadas anteriormene: trata-se de mostrar que o critério para definir comportamentos propositados não pode ser inferido pela observação sistemática de uma tendência para um estágio final. A convergência para um determinado estado final pode fornecer evidências para supor que alguns comportamentos dirigem-se para ele, embora não nos digam em que consiste uma ação propositada. Esta mesma deficiência apontada nos três autores analisados abre caminho para o quarto momento (Cap. 6) da exposição de Woodfield, que consiste num balanço das principais dificuldades e embaraços das teorias discutidas.

No capítulo 6, Woodfield rediscute bre- 
vemente as teorias abordadas e procura completar a segunda parte de seu trabalho ressaltando em que sentido elas são norteadas por um pressuposto comum. Tal pressuposto - que consiste na identificação dos comportamentos propositados com a mera sistematicidade de um padrão de movimentos que converge para um estágio final - , tem como resultado o fracasso parcial dessas teorias.

Na terceira parte (Caps. 7 e 8) Woodfield discute o conceito de função, investigando as diferenças e semelhanças entre funções, fins e metas, e questionando por que tais noções são chamadas teleológicas. Três problemas são principalmente tratados nesta parte. $\mathrm{O}$ primeiro deles, denominado pelo autor como problema de Hempel, consiste em saber por que apenas alguns elementos de um conjunto de atividades são considerados funções e outros apenas acidentais. O segundo problema, denominado problema de Nagel, questiona porque atribuímos funções a parte de determinados sistemas (por exemplo, organismos) mas não a partes de outros sistemas (por exemplo, o Sistema Solar). O terceiro problema diz respeito às explicações funcionais. Atribuir funções a um sistema equivale a dar uma explicação do comportamento desse sistema? Em que medida a explicação para algo é fornecida pela determinação de seus efeitos?

Para tratar estas questões Woodfield começa por fazer uma distinção entre enunciados de função (function-statements) como por exemplo, "a função do coração é circular o sangue" - e TDs funcionais - como por exemplo "o coração bate a fim de circular o sangue”. A seguir ele analisa o que significa atribuir uma função $F$ a $X$ quando X é um artefato ou é parte de um sistema biológico. O primeiro caso abrange aquelas funções que o autor chama de funções artificiais. A elas nos referimos quando dizemos, por exemplo, que a função de um coador de chá é coar chá. O segundo caso diz respeito às atribuições de funções naturais - isto é, funções de partes de sistemas biológicos. De acordo com o ponto de vista mais amplamente aceito (a concepção evolucionista) um enunciado de função natural do tipo "a função do coração é circular o sangue" deve, em linhas gerais, ser analisado como "o coração circula o sangue, e circular o sangue contribui para a sobrevivência e a reprodução do organismo de que ele é parte". Woodfield critica e acaba por rejeitar esta concepção evolucionista. Seus argumentos, entretanto, não nos parecem convincentes, uma vez que eles se apóiam, quase que exclusivamente, em um único contra-exemplo de eficácia duvidosa. Este exemplo, emprestado de R. Sorabji*, consiste na idéia de um mecanismo que inibisse a dor num caso de ataque cardíaco letal. Este mecanismo teria uma função - que Woodfield denomina "função de luxo" (luxury function) - qual seja, a de evitar a dor, embora não contribuísse para a sobrevivência ou reprodução do organismo. Este contra-exemplo parece estar em desacordo com nosso conceito intuitivo de função, a menos que adotássemos uma posição projecionista, o que Woodfield certamente recusaria.

Tendo rejeitado a concepção evolucionista de função, Woodfield propõe uma outra baseada na idéia de algo que é intrinsecamente bom para um organismo ou sistema. Na p. 130 ele diz: "As funções orgânicas de $\mathrm{S}$ fazem bem a $\mathrm{S}$ por promoverem os fins naturais de $\mathrm{S}$, entendendo-se por "fins" os estados ou processos ou atividades que são intrinsicamente bons para S". É nesse sentido que ele diz, por exemplo, que circular o sangue é uma função do coração, porque isso contribui para a sobrevivência e a sobrevivência constitui, para um ser vivo, um bem natural. Já os objetos inorgânicos tais como pedras, montanhas, etc. não têm funções para a Terra ou o Sistema Solar, porque seria inapropriado considerar que os primeiros podem fazer bem para os últimos, dado que a classe das entidades suscetíveis de serem beneficiadas compreende apenas as coisas vivas.

* Sorabji, R. Function. Phil. Quarterly, 14, 1964. 
Esta concepção de função natural, que tem como ponto de apoio a idéia de bem natural, resolve, no entender de Woodfield, o problema de Nagel (o segundo probema acima enunciado).

Tal concepção apresenta, a nosso ver, dois defeitos que não se verificam na abordagem evolucionista. O primeiro é que seu conceito de função envolve um julgamento valorativo a respeito daquilo que pode ser considerado bom para um sistema. Como o próprio autor admite, isso introduz um fator subjetivo na avaliação dos enunciados de função. O segundo defeito pode ser evidenciado - ao estilo do autor através de contra-exemplos. Woodfield admite que o ruído cardíaco deveria ser considerado uma função do coração, caso ele tivesse algum efeito benéfico para o organismo. Parece não lhe ocorrer, entretanto, que o ruído cardíaco na verdade, tem um efeito benéfico para os seres humanos nos dias de hoje. Ninguém ignora que tal ruído é útil em diagnósticos médicos, servindo como indicador do bom ou mal funcionamento do coração. Nem por isso, contudo, se considera que a produção de sons constitui uma função deste órgão.

O tratamento dispensado por Woodfield ao tópico das funções se completa com a análise que ele propõe para as TDs funcionais. Estas TDs - contrariamente aos enunciados de função, os quais envolvem elementos subjetivos - são considerados pelo autor como explicativos. Isso porque as TDs não afirmam apenas que " $\mathrm{X}$ constitui um bem para o sistema"; elas afirmam que "X existe porque ele faz algum bem para o sistema". As TDs funcionais especificam uma função e afirmam que tal função constitui uma razão da existência do elemento em questão. Elas afirmam, por exemplo, que o batimento cardíaco não representa apenas algo que é bom para os organismos vivos, mas que ele existe somente na medida em que contribui para a sobrevivência dos mesmos. Assim Woodfield julga que, ainda que elementos valorativos participem das explicações funcionais, sua participação ocorre apenas como um fator indicativo da conexão causal que se opera entre o elemento funcional (por exemplo, o batimento do coração) e o bom desempenho do sistema (sobrevivência do organismo). Para isso, no entanto, Woodfield tem de restringir a classe dos elementos que constituem bens para um sistema à sobrevivência e reprodução. Mas isso torna sua análise desnecessariamente complexa, uma vez que o elemento valorativo passa a ser aparentemente redundante. Dado que, como o próprio autor reconhece, apenas dois fins biológicos - sobrevivência e reprodução - sustentam sua interpretação, não vemos em que ela difere em essência da abordagem evolucionista.

Na quarta parte (Caps. 9-11) é retomado o problema da análise do comportamento propositado. O capítulo 9 é uma tentativa de desenvolver uma teoria externalista deste tipo de comportamento, isto é, uma teoria que não faça referência a estados internos da entidade que realiza o comportamento. O problema pode ser apresentado como consistindo em formular uma definição satisfatória do conceito de propósito. Conforme foi visto na segunda parte de Teleology, a idéia fundamental das teorias comportamentais consiste em conceber os propósitos com focos de comportamento plástico. A conclusão a que se chegou é que a condição de plasticidade não é suficiente, e só é, possivelmente, necessária em casos não-problemáticos de comportamento propositado. A estratégia do capítulo 9 consiste em explorar essa possibilidade e valendo-se do conceito de função natural examinado na terceira parte - corrigir a insuficiência mencionada, incluindo-se uma nova condição referente ao conceito de propósito.

De acordo com a primeira versão da teoria desenvolvida, uma ação, para ser um propósito, além de ser um foco de comportamento plástico, deve também ser uma função comportamental como por exemplo comer, beber, armazenar alimentos. (Na teoria externalista, apenas as ações - e não eventos ou estados - podem ser propositados). Diversas dificuldades enfrentadas por esta primeira versão da teoria são res- 
saltadas, e para superá-las alguns refinamentos são propostos, com a introdução das noções de propósitos subsidiários, derivados, etc. A relevância disso entretanto é questionável, pois a seguir o autor apresenta a crítica à teoria externalista, e esta nada tem a ver com as dificuldades levantadas: ela se refere a um aspecto fundamental da teoria e conduz a sua rejeição. $\mathrm{O}$ argumento de Woodfield é que a teoria externalista confunde verdades contingentes com verdades necessárias: ainda que não se possa fornecer exemplos reais, é concebível a existência de organismos que tenham propósitos que não sejam funções comportamentais (lembrando que uma função comportamental deve necessariamente ter um efeito benéfico para o organismo), nem se encaixe em nenhum outro dos tipos de propósitos sugeridos. Um exemplo hipotético elaborado pelo autor é o de um bezerro afetado por uma anomalia genética que o leva a sugar a ponta do rabo da vaca ao invés de suas tetas. Essa ação seria um propósito, ainda que não tivesse o ef eito benéfico algum para o bezerro.

No capítulo 10 Woodfield finalmente apresenta a teoria de comportamento propositado que ele próprio sustenta, sem entretanto alegar originalidade: trata-se, segundo ele, do ponto de vista tradicional sobre a questão. É uma teoria mentalista - já que envolve atribuições de estados mentais, e portanto, um tipo especial de teoria internalista. O que ela afirma, em suma, é que as TDs propositais devem ser analisadas em termos de um modelo desejo/crença. Assim, o enunciado "Pedro tomou um antibiótico a fim de curar sua gripe”, por exemplo, deve ser interpretado como "Pedro tomou um antibiótico porque ele desejava curar sua gripe, e acreditava que tomar um antibiótico iria contribuir para curá-la”. Esta é a versão simplificada da análise. A existência de vários contra-exemplos a essa proposta torna necessária a inclusão de novas cláusulas, de tal modo que a análise completa para o exemplo acima assume a seguinte for- ma: "Pedro tomou um antibiótico porque ele desejava curar sua gripe, e acreditava que tomar um antibiótico iria contribuir para curá-la, e este par desejo/crença iniciou e sustentou um desejo de tomar um antibiótico, o qual depois de se aliar com a crença de que o momento era propício, deu origem a um estado interno que controlou a execução do ato de tomar antibiótico”. Em princípio, qualquer uma das versões desta análise excluiria da classe dos sistemas capazes de realizar comportamentos propositados todos aqueles aos quais não se pode verdadeiramente atribuir estados mentais, ou seja, plantas e animais primitivos, bem como qualquer sistema inorgânico. Isto não ocorre, entretanto, pois admite-se que estados internos análogos a desejos e crenças também possam dar origem a comportamentos propositados. Embora subscrevamos a análise proposta por Woodfield, parece-nos que ela não avança o suficiente, que as noções de desejo e crença podem ser tão problemáticas quanto a de comportamento propositado. Em Teleology pouco se diz que possa corrigir esta impressão; deve-se registrar contudo, a publicação mais recente de um artigo de Woodfield sobre este problema, no que se refere a noção de desejo*

O capítulo 11 discute uma segunda alternativa de teoria internalista, a que emerge da abordagem cibernética. A atribuição - por N. Wiener e outros ciberneticistas - de propósitos a máquinas com retroalimentação negativa (negative feed-back) sugere a identificação da classe dos comportamentos propositados com a classe dos comportamentos controlados por retroalimentação negativa. A opinião, a nosso ver correta, que Woodfield mantém em relação a esta proposta é de que um mecanismo de retroalimentação negativa explica como o comportamento de um sistema deve ser controlado para que ele realize um propósito, e não o que é para um sistema, ter um propósito. Assim, a abordagem cibernética não fornece uma análise do conceito de

* Woofield, A. - Desire, intentional content and teleological explanation. The Proceedings of the Aristotelian Society, New Series, 82: 69-87. 
comportamento propositado: ela supõe conhecido este conceito, e sugere uma explicação a respeito do modo de controle dos comportamentos propositados. Além do mais, contra-exemplos podem ser citados, como o caso de um peixe se debatendo a fim de escapar de uma rede. Ainda que tal comportamento seja propositado, nem todos os movimentos do peixe são controlados pelas informações sensoriais que ele recebe do meio-ambiente, não havendo assim um processo contínuo de retroalimentação. Este caso demonstra que nem todo comportamento propositado é controlado por retroalimentação negativa, embora a grande maioria na verdade, o seja. A conversa desta proposição também é def ensável, ainda que - em virtude da vagueza de nossas intuições a respeito do conceito de comportamento propositado - seja difícil encontrar casos nítidos de comportamentos controlados por retroalimentação negativa que não sejam propositados. Woodfield admite a possibilidade de que devam ser considerados como não-propositados os comportamentos de termostatos e outros servomecanismos simples (os casos paradigmáticos da abordagem cibernética). Argumenta ele que se não nos parece estranha a atribuição do propósito de manter a temperatura constante a um termostato, isso se deve, em parte, ao fato de que um termostato tem esta função, na medida em que foi construído por alguém com esta finalidade. Haveria assim uma indevida projeção do propósito do construtor no artefato, projeção esta explicável psicologicamente, porém, com certeza, imprópria.

A conclusão do livro (quinta parte, Cap. 12) principia com uma reformulação da análise das TDs propositais desenvolvida no capítulo 10. Esta reformulação incide sobre o elemento "desejo" do modelo desejo/crença: propõe o autor que uma expressão da forma "S deseja P" seja parafraseada como "S acredita que P é bom". Para isso, entretanto, é necessário estipular os sentidos que devem ser atribuídos aos termos "acredita" e "bom" neste contexto: se eles (especialmente o termo “bom”) são interpretados em seus sentidos usuais, en- tão a paráfrase não resulta adequada, pois é sabido que um indivíduo pode desejar realizar uma ação, como por exemplo fumar um cigarro, a qual ele não acredita que seja boa para ele. Deste modo (retomando o exemplo já utilizado) a análise de "Pedro tomou um antibiótico a fim de curar sua gripe" passa a ser "Pedro tomou um antibiótico porque ele acreditava que seria bom curar sua gripe, e que tomar um antibiótico iria contribuir para curá-la”.

A seguir Woodfield representa, esquematicamente, numa tabela o resultado acima, juntamente com as análises dos outros três tipos fundamentais de TDs, a saber, os que se referem as funções comportamentais, artificiais e naturais. Verifica-se então que as quatro análises têm em comum dois elementos, quais sejam, um elemento causal (expresso pelo termo "contribui") e um elemento valorativo (expresso pelo termo "bom"). Segundo Woodfield, esta semelhança justifica sua conclusão de que "os diferentes tipos de explicações teleológicas são variações sobre um único tema" (p. 205). Esse tema consiste, em suma, na idéia de que "algo ocorre porque é bom" (ibidem). Ou em outras palavras: "as TDs expressam a idéia de que as coisas ocorrem ou existem porque elas conduzem ou acredita-se que elas conduzem a algo que é bom" (p. 205). A justificação de Woodfield só tem valor, naturalmente, para quem aceita todas suas análises - o que não é o nosso caso, no que diz respeito as análises das TDs referentes às funções naturais. E mesmo do ponto de vista do autor, não nos parece válida sua justificação: a reformulação da análise das TDs propositais é um tanto forçada, especialmente na medida em que ela obriga a delimitação do sentido do termo "bom", diferenciando-o daquele utilizado pelo autor na análise das TDs funcionais. No caso, por exemplo, das TDs referentes a funções naturais, o termo bom foi empregado no sentido de algo que contribui para a sobrevivência ou reprodução dos organismos. Já nas TDs propositais, o termo "bom" se aplica a qualquer objeto de desejo, e nesse sentido, poderíamos considerar que do ponto de vista de 
um suicida, a morte é algo bom, na medida em que ele a deseja. Isso não se chocaria, entretanto, com a afirmação que Woodfield faz ao discutir as TDs funcionais, segundo a qual a morte não poderia, de maneira alguma, ser considerada um bem?

$\mathrm{Na}$ última parte do livro, Woodfield apresenta duas aplicações de suas teorias a respeito da teleologia. São discutidas as questões de se o universo tem um propósito e se a vida de uma pessoa tem um propósito. Com uma interessante discussão dessas questões o autor finaliza sua obra, que constitui sem dúvida uma valiosa contribuição no sentido de clarificar a nature- za da teleologia. Convém entretanto ressaltar que muitas vezes, no seu empenho de elaborar uma abordagem rigorosa dos temas tratados, Woodfield se detém em detalhes e minúcias que tornam a leitura do Teleology um tanto quanto penosa. Em contrapartida, na exposição e discussão de algumas teorias, ele pressupõe um conhecimento prévio das concepções que são criticadas, limitando-se a uma exposição sumária de pontos de vista, o que por vezes também dificulta a tarefa do leitor. Mas apesar das críticas que acabamos de esboçar, recomendamos vivamente a leitura de Teleology pelas numerosas contribuições positivas e interessantes que podemos extrair dessa obra. 